primary outcome variable, consideration of PA, defined as clearly-documented consideration of PA in attending or trainee note OR skeletal survey ordered OR child-abuse team consult ordered. Co-variates examined as well.

Results Characteristics of 529 patients and physicians are displayed in Table 1. For the entire cohort, consideration of $\mathrm{PA}$ occurred in 346 (65\%), whereas consideration in infants $<6$ months of age occurred in 194 (78\%). EMR clearlydocumented consideration of PA occurred in 288 (54\%). Characteristics associated with greater odds for consideration of PA after covariate adjustment (OR and 95\% CI) included younger patient age (IQR of 12.1 to 38.7 weeks: 0.53 [0.33, $0.84]$ ), no history provided for injury $(9.41[3.88,22.82])$, softtissue injury $(4.95,[1.57,15.54])$, and male attending (1.84, $[1.12,3.01])$.

Conclusion PED physicians frequently do not consider PA in infants with fractures. Characteristics associated with consideration for PA include patient age, no history provided to explain the injury, soft-tissue injury, and male attending gender.

\section{Paediatric Intensive Care}

\section{0-096 NON-RESPIRATORY PELOD-2 SCORE IS A GOOD PREDICTOR OF MORTALITY IN CHILDREN WITH ACUTE RESPIRATORY FAILURE}

${ }^{1} S$ Leteurtre, ${ }^{2} \mathrm{~A}$ Duhamel, ${ }^{2} \mathrm{~V}$ Deken, ${ }^{1} \mathrm{C}$ Le Reun, ${ }^{3} \mathrm{~J}$ Lacroix, ${ }^{4} \mathrm{~F}$ Leclerc, ${ }^{1} \mathrm{Gfrup} .{ }^{7} \mathrm{PICU}$, CHRU de Lille, LILLE Cedex, France; ${ }^{2}$ Department of Biostatisitics, CHRU de Lille, LILLE Cedex, France; ${ }^{3}$ PICU, Sainte Justine Hospital, Montréal, Canada; ${ }^{4}$ Paris, GFRUP: Groupe Francophone de Reanimation Et Urgences Pediatriques, France

\subsection{6/archdischild-2014-307384.163}

Background and aim Multiple organ dysfunction, not respiratory failure, is the major cause of death in children with ALI or ARDS. This study was undertaken to estimate the predictive value of death of the non-respiratory Paediatric Logistic Organ Dysfunction (PELOD)-2 (NRespPELOD-2) in children with acute respiratory failure (ARF).

Methods Analysis of the database of the recently published PELOD-2. All consecutive children (excluding neonates) admitted to 9 PICU in France and Belgium (June 2006-October 2007) and having ARF. We prospectively collected data on variables considered for the PELOD-2 score during PICU stay: days 1, 2, 5, 8, 12, 16 and 18, plus PICU discharge. For each variable of the PELOD-2 score, the most abnormal value observed during time points was collected. Outcome was vital status at PICU discharge. We used AUCs to estimate the discrimination and Hosmer-Lemeshow goodness-of-fit tests to estimate calibration of the PELOD-2 and the NRespPELOD-2 scores, with correction for the optimism bias using a bootstrap resampling method.

Results We included 1572 patients (median age: 20.6 months; mortality: 9.5\%). Discrimination of the PELOD-2 and the NRespPELOD-2 was excellent (AUC $=0.93$ and 0.92, respectively) and calibration was good ( $\mathrm{p}=0.45$ and 0.27 , respectively). The four NResp organ dysfunctions were closely related to the risk of mortality $(\mathrm{p}<0.001)$.

Conclusions Our study demonstrates that the NRespPELOD-2 score of the entire PICU stay is highly predictive of death in children with ARF of whom $94.3 \%$ were invasively ventilated. It could represent the non-respiratory organ failure definition tool claimed by the international experts on paediatric ARDS.

\section{0-097 CLINICAL SCORE TO PREDICT OUTCOME IN CONGENITAL DIAPHRAGMATIC HERNIA; RESULTS OBTAINED FROM AN INTERNATIONAL MULTICENTER STUDY}

${ }^{1} \mathrm{KG}$ Snoek, ${ }^{2} \mathrm{C}$ Capolupo, ${ }^{2} \mathrm{~F}$ Morini, ${ }^{1} \mathrm{RMH}$ Wijnen, ${ }^{3} \mathrm{~K} \mathrm{KM}$ Reiss, ${ }^{2} \mathrm{P}$ Bagolan, ${ }^{1} \mathrm{H}$ IJsselstijn, ${ }^{1} \mathrm{D}$ Tibboel. 'Department of Paediatric Surgery and Intensive Care, Erasmus MC Sophia Children's Hospital, Rotterdam, Netherlands; '2Department of Medical and Surgical Neonatology, Bambino Gesu Children's Hospital, Rome, Italy; ${ }^{3}$ Department of Neonatology, Erasmus MC Sophia Children's Hospital, Rotterdam, Netherlands

\subsection{6/archdischild-2014-307384.164}

Background In congenital diaphragmatic hernia $(\mathrm{CDH})$ reliable postnatal predictors of outcome are scarce. Score for Neonatal Acute Physiology-II (SNAP-II) (Richardson, 2001) has been validated to predict mortality in newborns. We hypothesised that higher SNAP-II scores are found in non-survivors, those who need extracorporeal membrane oxygenation (ECMO), and those who develop chronic lung disease (CLD), defined as oxygen dependency at day 28.

Methods In a prospective, randomised controlled multicenter trial initiated by the Euroconsortium (VICI-trial, NTR 1310), neonates born between November 2008 and December 2013, were randomised for initial ventilation strategy (either high-frequency oscillation or conventional mechanical ventilation). Prenatal, perinatal and postnatal data including SNAP-II scores were collected. Mann-Whitney U test was used for analyses. Data were presented as $\mathrm{n}(\%)$ and median (IQR).

Results Of the 173 included patients, 46 patients (26.6\%) died, $39(22.5 \%)$ underwent ECMO, and 38 patients (29.9\%) of the survivors developed CLD. Overall, the SNAP-II score was 22.5 (10 to 37). In non-survivors SNAPP-II score was 40.0 (32.0 to 54.5 ) and 16.5 (7.8 to 26.5 ) in survivors ( $p<0.001)$. It was 35.0 (30.0 to 46.0) in ECMO treated patients and 19.0 (9.0 to $32.0)$ in patients without ECMO need $(\mathrm{p}<0.001)$. Survivors with CLD had SNAP-II score of 25.5 (21.0 to 35.5) and those without CLD 13.0 (5.0 to21.0) $(\mathrm{p}<0.001)$.

Conclusions In this prospective multicenter study, we showed that in CDH patients SNAP-II scores may not only be useful to predict mortality but also to identify patients who need ECMO or are at risk for development of CLD.

\section{Pharmacology I}

\section{0-098 POTENTIALLY HARMFUL EXCIPIENTS IN MEDICINES PRESCRIBED IN NEONATAL INTENSIVE CARE UNITS (NICU) - PRODUCT SUBSTITUTION AS A WAY FORWARD}

${ }^{1} \mathrm{G}$ Nellis, ${ }^{2}$ I Lutsar, ${ }^{1} \mathrm{H}$ Varendi, ${ }^{3} \mathrm{~J}$ Lass, ${ }^{4} \mathrm{MA}$ Turner, ${ }^{5} \mathrm{~T}$ Metsvaht. ${ }^{1}$ Neonatal Unit, Children's Clinic of Tartu University Hospital, Tartu, Estonia; ${ }^{2}$ Department of Microbiology, Tartu University, Tartu, Estonia; ${ }^{3}$ Pharmacy Department, Tartu University Hospital, Tartu, Estonia; ${ }^{4}$ Neonatal Unit, Liverpool Women's Hospital, Liverpool, UK; ${ }^{5}$ Paediatric Intensive Care Unit, Tartu University, Hospital, Tartu, Estonia

\subsection{6/archdischild-2014-307384.165}

Background Excipients are essential for many medicines. Some have been associated with significant consequences in neonates. We aimed to identify substitution possibilities among medicines used in European neonates in order to minimise the administration of potentially harmful excipients of interest (EOI).

Methods A 3-day survey recording all medicines prescribed to neonates was performed in European NICUs. Based on existing toxicity data in neonates the EOI included parabens, polysorbate 80, propylene glycol, benzoates, saccharin sodium, sorbitol, 
ethanol and benzalkonium chloride. Opportunities for product substitution were defined as EOI-containing formulations for which an EOI-free product was reported in the survey with identical active pharmaceutical ingredient (API), galenic form and strength.

Results Of 31 invited European countries 20 with 115 NICUs responded. A total of 564 trade names (TN) with 53 APIs were used in more than $10 \%$ of units. EOI containing formulations ( $\mathrm{n}$ = 151) were used for 31 APIs, found overall in 363 TNs. Compared to parenteral forms $(50 / 199 ; 25 \%)$, enteral $(83 / 130 ; 64 \%)$ and topical TNs $(18 / 34 ; 53 \%)$ contained EOI more frequently (OR; 95\% CI 5.3; 3.3-8.5 and 3.4; 1.6-7.1, respectively). An EOI free substitution was available for $31 / 50$ parenteral (63\%), $17 / 83$ enteral (21\%) and 3/18 topical (17\%) TNs. Overall, 51/ 151 (34\%) TNs with EOI could be replaced; substitution was possible in $92 / 151(61 \%)$ of cases if the requirement for identical API strength was ignored.

Conclusions EOI-free formulations available on the European market could be used to reduce the number of TNs with EOI by at least a third.

\section{0-099 THE IMPACT OF BREASTFEEDING ON THE INCIDENCE AND SEVERITY OF NEONATAL ABSTINENCE SYNDROME}

${ }^{1} \mathrm{~K}$ Allegaert, ${ }^{2} \mathrm{JN}$ van den Anker. ${ }^{1}$ Neonatal Intensive Care Unit, University Hospitals Leuven, Leuven, Belgium; 'Intensive Care, Erasmus MC Sophia's Children's Hospital, Rotterdam, Netherlands

\subsection{6/archdischild-2014-307384.166}

Background and aims In light of the current epidemic in the abuse of opioids, a major increase in neonates with neonatal abstinence syndrome (NAS) is likely. Incorporation of breastfeeding as a first pillar of treatment of NAS seems appropriate. We aimed to quantify the impact of breastfeeding on the incidence and severity of NAS.

Methods Pooling of published NAS cohorts, with specific emphasis on the impact of breastfeeding on the incidence (yes/no opioid administration) and duration (duration opioids, duration hospitalisation) of NAS.

Results Three studies [1-3] were retrieved and resulted in a pooled dataset of 400 neonates (218 breastfed, 54.5\%). There is a significant reduction in NAS (54 vs 77\%, number needed to treat 5-6). The same trends are observed when the duration of opioid treatment (difference -18 to -23 days) or the length of hospital stay (difference -4 to -10 days) are considered.

Conclusions Breastfeeding is associated with a clinical significant reduction on both the incidence and the duration of NAS in opioid exposure newborns. Incorporation of breastfeeding as a first pillar of treatment for relieving the NAS symptoms seems to be a very natural, and effective way of addressing this.

\section{REFERENCES}

Abdel-Lalif ME et al. Pediatrics 2006

Wachman EM et al. JAMA 2013

Welle-Strand GK et al. Acta Paediatr 2013

\section{0-100 RELATIONSHIP BETWEEN ADVERSE DRUG REACTIONS AND OFF-LABEL/UNLICENSED DRUG USE IN HOSPITALISED CHILDREN. EREMI STUDY}

${ }^{1}$ KA Nguyen, ${ }^{2} Y$ Mimouni, ${ }^{2} \mathrm{~A}$ Lajoinie, ${ }^{3} \mathrm{~N}$ Paret, ${ }^{2} \mathrm{~S}$ Malik, ${ }^{2} \mathrm{~L}$ Milliat-Guittard, ${ }^{2} \mathrm{~L}$ El-Amrani, ${ }^{2} \mathrm{C}$ Castellan, ${ }^{2} \mathrm{AM}$ Schott, ${ }^{3} \mathrm{~T}$ Vial, ${ }^{2} \mathrm{~B}$ Kassai. ${ }^{1}$ Neonatal Intensive Care Unit and Neonatology, Hospices Civils de Lyon/Hôpital Femme Mère Enfant, Lyon, France; ${ }^{2}$ Clinical Pharmacology, Hospices Civils de Lyon/EPICIME/CIC 1407/Hôpital Femme Mère
Enfant/UMR 5558/CNRS/Lyon 1 University, Lyon, France; ${ }^{3}$ Pharmacovigilance Center of Lyon, Hospices Civils de Lyon/Lyon 1 University, Lyon, France

\subsection{6/archdischild-2014-307384.167}

Background and aim To date few studies have shown a significant association between the off-label drug use and adverse drug reactions.

(ADRs). The main aims of this study are to evaluate the relationship between adverse drug reactions and unlicensed or offlabel drugs prospectively in hospitalised children and to provide more information on prescribing practice, the amplitude, nature and consequences of unlicensed or off-label drug use in paediatric inpatients.

Methods In this ongoing multi-centre prospective study, the French summaries of product characteristics in Theriaque (a prescription products guide) are being used as a primary reference source for determining paediatric drug labelling. Detection of ADRs is carried out by health care professionals and research groups using a trigger tool and patients' electronic health records. The causality between suspected ADRs and medication is evaluated using the Naranjo and the French methods of imputability.

Preliminary results for a 6 month period: $40 \%$ of the 73 detected ADRs were estimated as severe. 1498 patients have been included.

Conclusions This is the first large multi-centre prospective study in France that evaluates the relationship between adverse drug reactions and unlicensed or off-label drugs in hospitalised children. This study will help to identify the risk factors that could be used to adjust preventive actions in children care, guide future research in the field and increase the awareness of physicians in detecting and declaring ADRs. This study is funded by l'ANSM (French national agency of drug security).

\section{0-101 NUMBER OF PROCEDURES AND ANALGESIC THERAPY IN NEONATES ADMITTED TO NICUS: EPIPPAIN 2 STUDY}

R Carbajal ${ }^{1},{ }^{1} \mathrm{E}$ Courtois, ${ }^{2} \mathrm{~S}$ Droutman, ${ }^{3} \mathrm{JF}$ Magny, ${ }^{4} \mathrm{Z}$ Merchaoui, ${ }^{5} \mathrm{X}$ Durrmeyer, ${ }^{6} \mathrm{C}$ Roussel, ${ }^{7} \mathrm{~V}$ Biran, ${ }^{8} \mathrm{~S}$ Renolleau, ${ }^{9} \mathrm{~L}$ Desfrere, ${ }^{10} \mathrm{~F}$ Castela, ${ }^{11} \mathrm{~N}$ Boimond, ${ }^{12} \mathrm{D}$ Mellah, ${ }^{13} \mathrm{P}$ Bolot, ${ }^{14} \mathrm{~A}$ Coursol, ${ }^{15} \mathrm{M}$ El Ayoubi, ${ }^{16} \mathrm{~S}$ Eleni, ${ }^{17} \mathrm{D}$ Brault, ${ }^{18}$ E Epippain 2 Study Group, ${ }^{19} \mathrm{P}$ Cimerman, ${ }^{20} \mathrm{KJS}$ Anand. 'Emergency Department, Hôpital Armand-Trousseau, Paris, France, ${ }^{2}$ NICU, Hôpital André Grégoire, Montreuil, France; ${ }^{3} \mathrm{NICU}$, Institut de Puériculture Et de Périnatalogie, Paris, France, ${ }^{4}$ NICU, Hôpital Bicêtre, Le Kremlin Bicêtre, France; ${ }^{5}$ NICU, Intercommunal de Créteil, Créteil, France; ${ }^{6}$ NICU, Hôpital Antoine Béclère, Clamart, France; ${ }^{7}$ NICU, Hôpital Robert Debré, Paris, France; ${ }^{8}$ NICU, Hôpital Armand-Trousseau, Paris, France; ${ }^{9} \mathrm{NICU}$, Hôpital Louis Mourier, Colombes, France; ${ }^{10} \mathrm{NICU}$, Intercommunal de Poissy, Poissy, France; ${ }^{11}$ NICU, Hôpital Necker, Paris, France; ${ }^{12}$ NICU, Centre Hospitalier de Meaux, Meaux, France, ${ }^{13}$ NICU, Centre Hospitalier de Saint-Denis, SaintDenis, France; ${ }^{14}$ NICU, Centre Hospitalier René Dubos, Cergy Pontoise, France; ${ }^{15}$ NICU, Hôpital Cochin Port Royal, Paris, France, ${ }^{16}$ NICU, Hôpital Louise Michel, Evry, France; ${ }^{17}$ NICU, Centre Hospitalier Victor Dupouy, Argenteuil, France, ${ }^{18}$ Epippain 2 Study Group, Epippain 2 Study Group, Paris, France, ${ }^{19}$ Centre National de Ressources de Lutte Contre La Douleur, Hôpital Armand-Trousseau, Paris, France, ${ }^{20}$ Department of Pediatrics Critical Care Medecine Division, University of Tennessee Health Science Center, Memphis, USA

\subsection{6/archdischild-2014-307384.168}

Background Neonates admitted to NICUs are frequently subjected to invasive procedures, often with sub-optimal analgesic treatment.

Objective To determine the number of invasive procedures and analgesic practices in NICUs.

Methods Invasive procedures and corresponding analgesic therapies on days 1-14 of NICU admission were prospectively 